\title{
Experimental Investigation of a Multi Effect Membrane Based Regenerator for High Concentration Aqueous LiCL Solution as Desiccant
}

\author{
Nirmalya Datta, Anutosh Chakraborty \\ Nanyang Technological University \\ 50 Nanyang Avenue, Singapore 639798 \\ nirmalya001@ntu.edu.sg; achakraborty@ntu.edu.sg
}

\begin{abstract}
Membrane based energy exchange has been into air-conditioning and desalination research for quite some time due to its enhanced abilities to separate the desiccant solution channel from the air channel and efficient energy exchange. However, a V-MEMD i.e. vacuum multi-effect membrane desiccant regenerator is under sub-atmospheric pressure, unlike conventional liquid to air membrane energy exchange (LAMEE) or run around membrane energy exchange (RAMEE) dehumidifier. This study aims to provide a thermal performance analysis of a V-MEMD test bed for the regeneration of desiccant solution. The regeneration system is used for concentrating the desiccant by removing water vapor from the solution. The energy recovery is carried out by multi-effect evaporation, and the mass transfer across the membrane is driven by low grade thermal and pressure gradient. This study analyzes the thermal performance and percentage increase in desiccant concentration for highly concentrated aqueous lithium chloride solutions when subjected to V-MEMD regeneration. Different operating parameters were examined experimentally to determine the optimum performance of high concentration desiccant solutions. Further comparisons of regenerator performance for different concentrations of $\mathrm{LiCl}$ are presented along with analysis.
\end{abstract}

Keywords: Multi-effect evaporator, Desiccant solution regenerator, Thermal performance, Concentration analysis, Lithium chloride, desalination, Microporous hydrophobic membrane

\section{Introduction}

The main factor that determines the effectiveness of an air-conditioning system is its ability to control the humidity of the indoor air within a range for human comfort. The conventional vapor compression system has been long used for this purpose. Buildings are responsible for about $40 \%$ of energy consumption world-wide [1-3]. Air-conditioning accounts for $60 \%$ of energy consumptions in buildings. These systems are usually driven by electricity and carries out dehumidification and cooling of supply air by direct expansion (DX) cooling coil and vapor compression. The disadvantage of the process is that a lot of energy is required to handle the sensible heat as well as latent heat of vaporization.

Liquid desiccant air conditioning (LDAC) has long been proposed as an alternative or as integration to heating ventilation air condition [4-6]. The advantage of LDAC is that the dehumidification of supply air to acceptable relative humidity $(\mathrm{RH})$ is performed first, and then the dehumidified air is cooled conventionally. In this process, a liquid desiccant driven by low grade heat source removes the relative humidity value of air to acceptable range and as a result the cooling part of the system has to handle only the sensible heat, thereby reducing the energy consumption for cooling the water vapor below its dew point (removing latent heat). Another advantage of this method is the utilization of the liquid desiccant to store the latent heat [7].

The use of hydrophobic membranes is attracting more attention in liquid desiccant based dehumidification/regeneration system because of its ability to completely prevent the carryover of desiccant vapors into the air stream and thereby lead to corrosion of the wetted areas in the system. LAMEE (liquid-air-membrane energy exchange) and RAMEE (run-around-membrane-energy-exchange) are the two most type of membrane technology, and they gain importance in research [4, 8-11].

In this experimental study, a V-MEMD (vacuum multi effect membrane distillation) system employing hydrophobic microporous membrane made of Polytetrafluoroethylene (PTFE), a patented and product of memsys ${ }^{\circledR}$ for desalination, is 
used as a desiccant regenerator [12]. The regenerator concentrates the liquid desiccant by removing water vapor across the membrane and recovery of energy due to the multi-effect design, which is stored in the desiccant, thereby reducing the overall energy consumption [13]. The objective of the experiment is to study the effectiveness and the thermal performance of the regenerator using highly concentrated aqueous lithium chloride $(\mathrm{LiCl})$ solution as the desiccant solution. This paper also presents the comparative analysis of performance and effectiveness of the V-MEMD regenerator for different feed concentrations of the liquid desiccant.

\section{Experimental Investigation}

A single stage of the V-MEMD system comprises membrane module and foil modules and they are separated by desiccant flow channel as shown in Figure 1. The modules are welded together with spacer between polypropylene (PP) foil frame and the PTFE membrane frame, each stage comprises six PP foil and five membrane frames. The spacer allows for uniform solution flow channel. A typical LDAC system consists of number of heat transfer fluid-solution-air stages depending upon the capacity of the LDAC. In this experimental study, a two stage system is used.

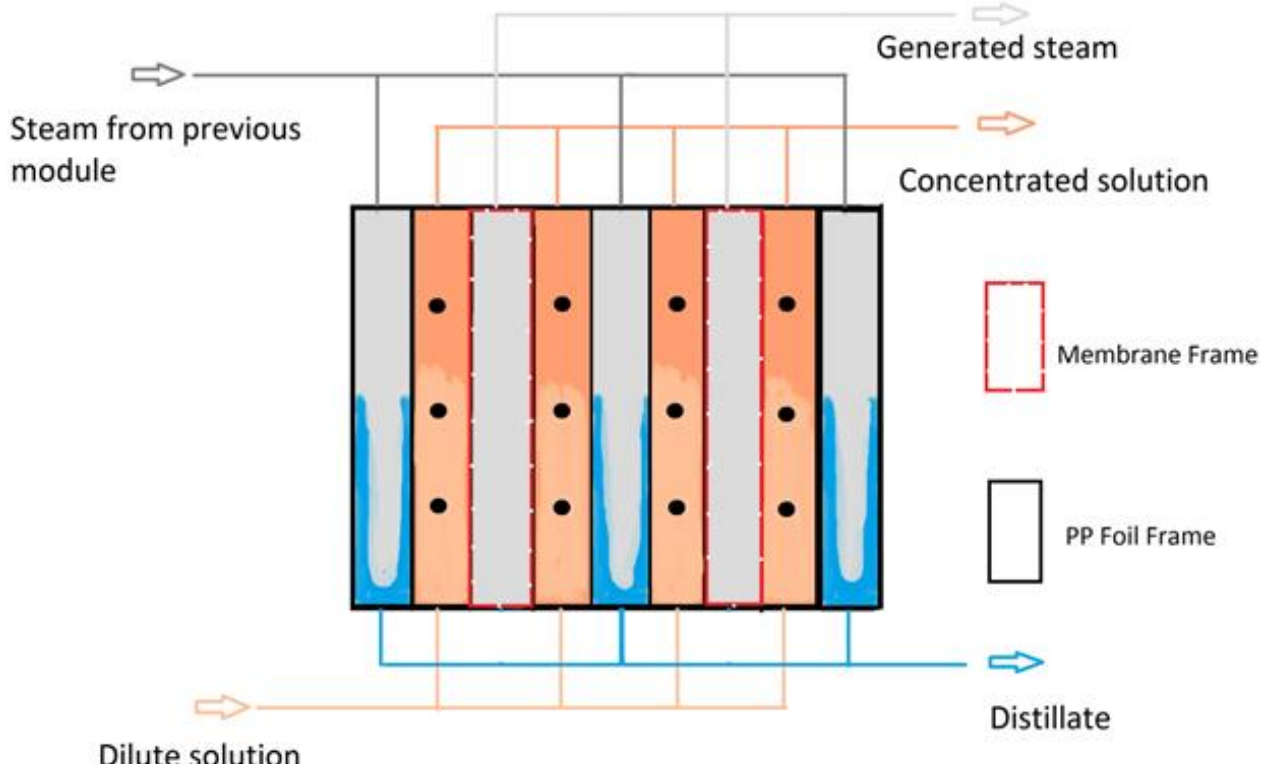

Fig. 1: Schematic of a membrane based regenerator operation.

The steam is generated in the steam riser and it travels via piping to the first stage PP foil frame where it condenses under the influence of the lower temperature liquid desiccant flowing in the adjacent spacer (forward feed flow). The contactless interaction between the high temperature of water flowing in the foil frame and low temperature solution flowing in the pressure leads to an increase in temperature of the salt solution. A part of thermal energy from steam condensation is used for generating more steam from the salt solution. The recovered heat along with the lower pressure creates a temperature gradient, consequently water vapor partial pressure gradient across the membrane. Steam is generated and transferred across the membrane; and is then passed on to the foil frame of the next module for condensation.

The heat and mass transfer from stage to stage by condensation and evaporation helps in recovery of the thermal energy allowing recovery of water, along with concentrating the feed salt solution in a multi-stage system under vacuum conditions. Further details are described by Wolfgang Heinzl, et al. [12].

\subsection{Experimental Set-up}

The V-MEMD regenerator is shown in Figure 2 is powered by solar energy. The vacuum tube solar collectors are integrated in the roof of the building along with hot water storage tanks. The hot water tanks of the solar collector system supplies the low grade heat for driving the multi effect regenerator. The multi stage regenerator is an integration of six key components, they are, the steam riser, distillation modules, condenser, heat exchangers and a vacuum pump. The steam riser is made up of PTFE membrane and the condenser is made up of PP foil. 
The hot water from the solar collector flows through the heat exchanger and a pump in the secondary loop of the heat exchanger circulates the hot water in the steam riser. The working of the multi-stage evaporator is well explained by Kumja, $M$ et al. [14] paper.

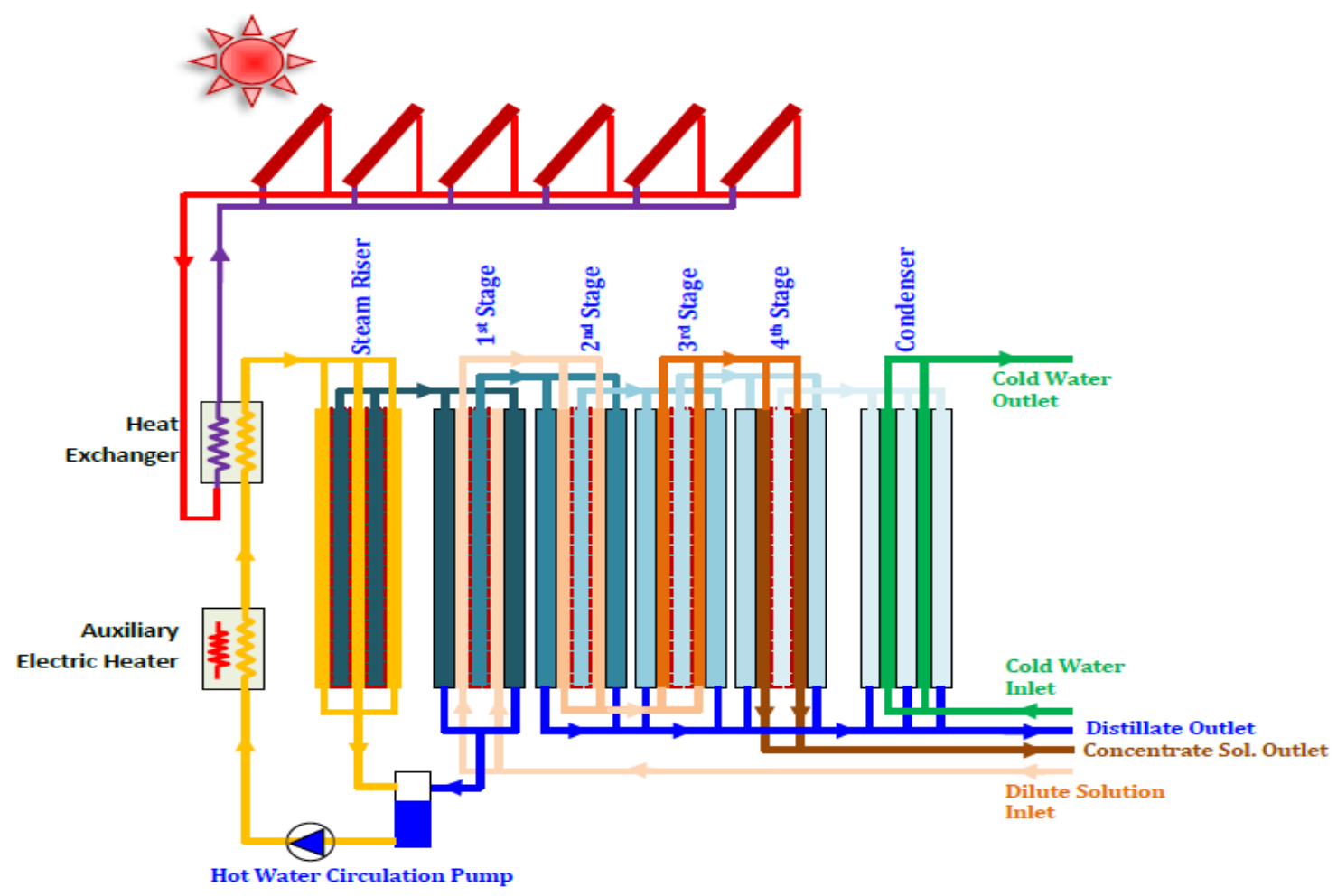

Fig. 2: Schematic diagram of a solar driven V-MEMD regeneration system.

The water loss due to condensation is made up by circulation of the condensate back to the steam riser. The rise in the desiccant temperature in the spacer is due to the latent heat of condensation of the steam in the foil module transferred through the foil via the convectional heat transfer. The temperature and pressure gradient across the membrane allows the loss of water vapor/steam from the salt solution across the membrane into the membrane module. Thus, there is an increase in concentration of the salt solution which then flows to the next stage for further concentration. In the second stage the steam generated in the membrane frame of the first stage is condensed in the foil frame of the second stage, the latent heat of condensation is partially recovered by the concentrated solution from the first stage.

\subsection{Materials}

The multiple stages of the regenerator along with the steam riser and the condenser are made from synthetic material to avoid the corrosive effects of the liquid desiccant salt solutions. The membrane modules comprises of hydrophobic PTFE membrane laminate ( functional layer : PTFE, back material: Polypropylene) with a reference pore size of $0.2 \mu \mathrm{m}$, and $0.12 \sim 0.2 \mathrm{~mm}$ thickness are used for the separation process. The desiccant salt used for the experiments and analysis was Lithium Chloride ( $\mathrm{LiCl})$ with a high mass fraction of $28 \% \sim 30 \%$.

\section{Results and Discussions}

The designs of the experiments are based on the variable operating parameters. A total of 8 experiments were conducted using aqueous solution of $\mathrm{LiCl}$ at $34 \%$ inlet concentration (mass fraction) for feed flow rates of $10 \mathrm{l} / \mathrm{hr}, 30 \mathrm{l} / \mathrm{hr}$ and $60 \mathrm{l} / \mathrm{hr}$. The heating source temperature was maintained in a range of $55^{\circ} \mathrm{C}$ to $80^{\circ} \mathrm{C}$. 


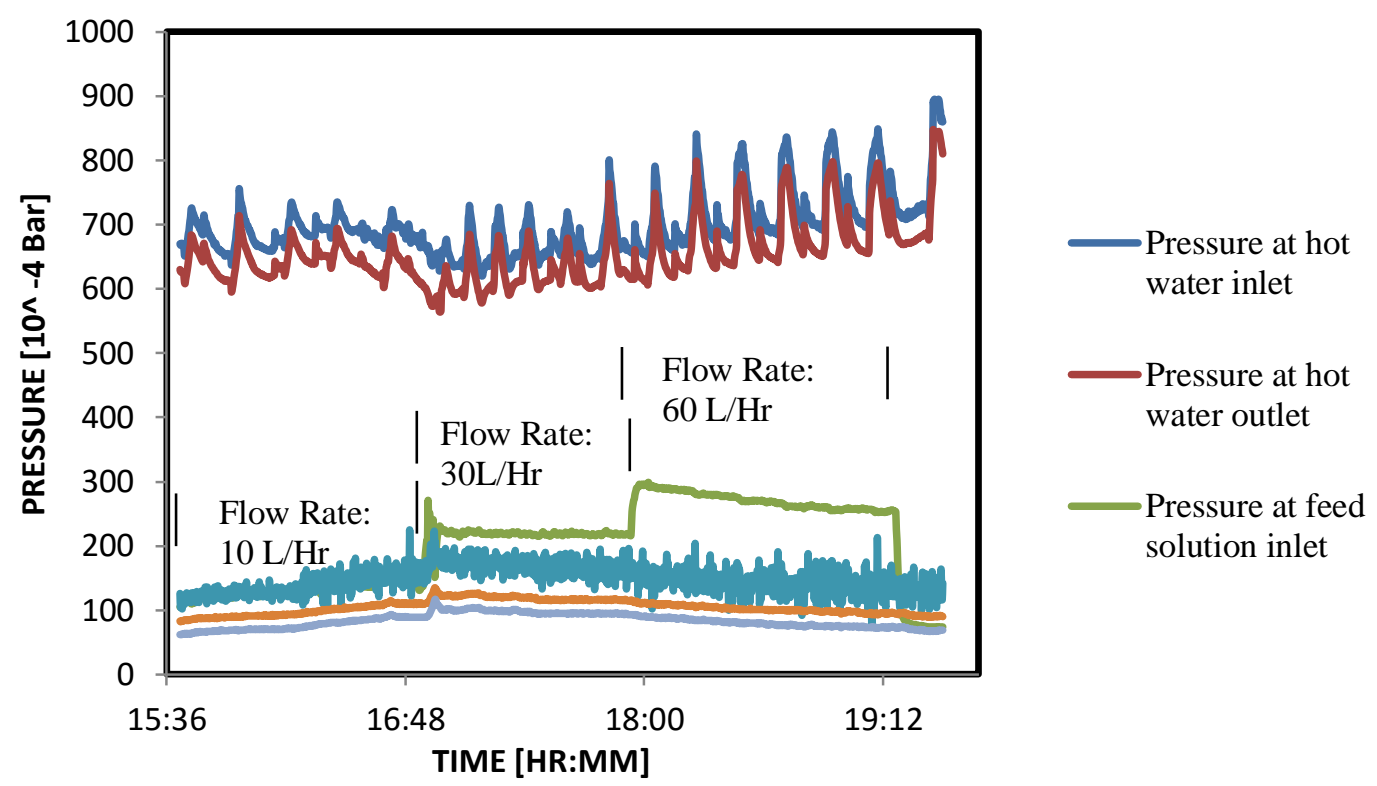

Fig. 3: Pressure profile v/s Time.

The Figure 3 shows the real time pressure variation profiles of the 2-stage V-MEMD regenerator with an operating condition of $34 \%$ inlet concentration versus the actual time of operation (24-hour format) respectively with feed flow rate varying between $101 / \mathrm{hr}$ to $601 / \mathrm{hr}$.

The change in concentration $\Delta C$ (in \%) is calculated on the basis of the following equation;

$$
\Delta C=|\operatorname{Cin}-\operatorname{Cout}|
$$

The thermal performance ratio is calculated based on the equation used by Kumja, M et al. [14].

$$
P R=\left(m_{\text {dist }} * h_{f g}\right) / H_{\text {in }}
$$

The heat energy input, $H_{\text {in }}(\mathrm{kW})$ is the heat energy input to the regenerator, $h_{f g}$ is the heat of vaporization and $m_{\text {dist }}$ is the mass flow rate of distillate $(\mathrm{kg} / \mathrm{sec})$. It is a function of hot water flow rate and the temperature difference between the hot water flowing in and out of the steam riser.

\subsection{Analysis of thermal performance ratio}

The variation of the thermal performance ratio with feed flow rate is shown in Figure 4 for the inlet solution of 34\% concentration. The result shows that the performance ratio varies from 0.29 to 0.57 depending on the feed flow rate. The PR is very low compared to conventional multi effect evaporator operating at lower desiccant solution concentration, which was measured roughly 2.0 [15]. The reason for the fall in the PR can be attributed to the lower thermal conductivity and lower vapor pressure of the desiccant solution at higher concentration [15-16]. However the performance ratio increases with an increase in the feed flow rate and also with the increase of the heating temperature.

\subsection{Analysis of thermal percentage change in concentration}

The variation of the change in concentration with the feed flow rate is shown in Figure 5, for $34 \%$ concentration at inlet salt solution. It can be observed from this figure that the change in concentration is higher at lower feed flow rates and decreases with an increase of the feed flow rate. The result shows the change in concentration varies from $9.7 \%$ to $2.4 \%$ with the flow rate varying from $10 \mathrm{l} / \mathrm{hr}$ to $60 \mathrm{l} / \mathrm{hr}$. 


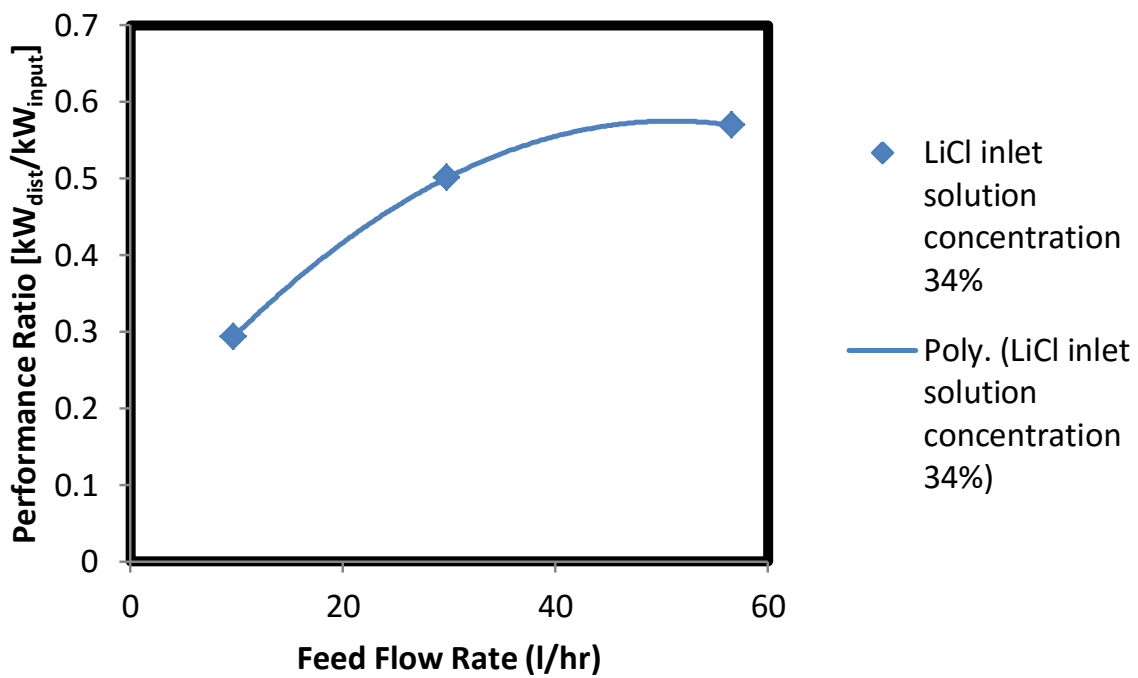

Fig. 4: Thermal performance ratio against feed flow rate at $34 \%$ feed concentration at inlet; heating temperature $\sim 80^{\circ} \mathrm{C}$.

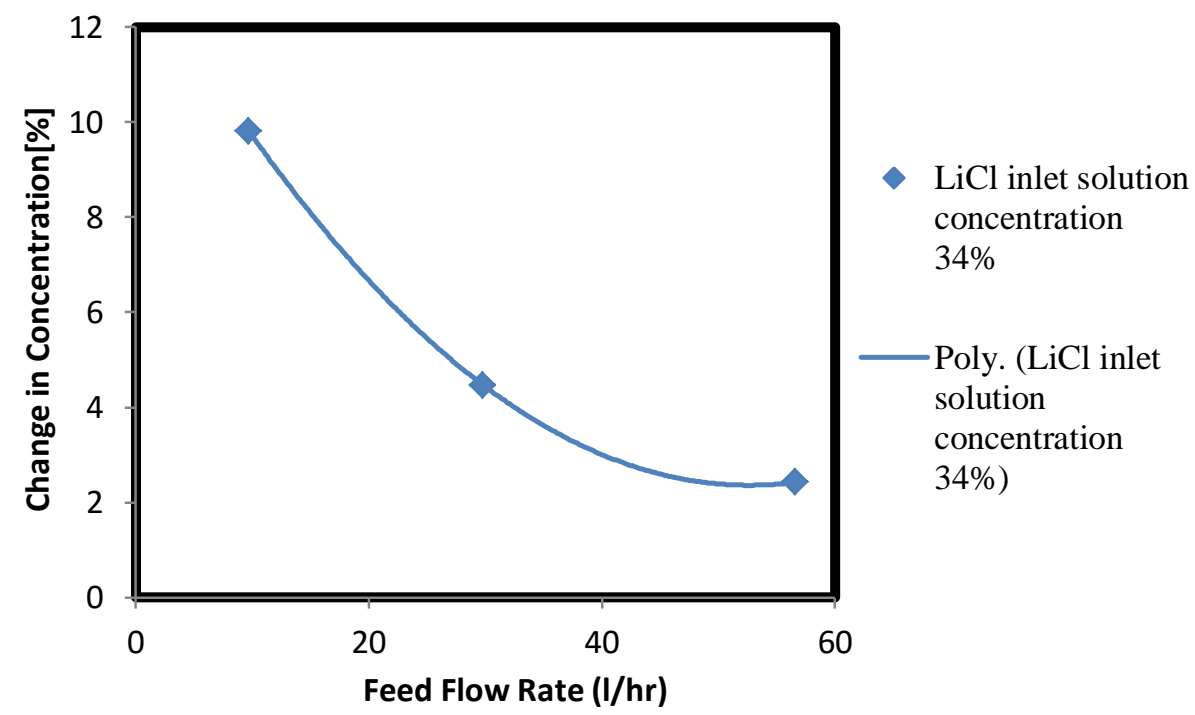

Fig. 5: Change in concentration of desiccant [\%] with varying feed flow rate at $34 \%$ inlet concentration; heating at $\sim 80^{\circ} \mathrm{C}$.

Figure 6 shows the variations of inlet and outlet concentrations for $34 \% \mathrm{LiCl}$ solution at inlet versus feed flow rate at the heating temperature $80^{\circ} \mathrm{C}$. It can be seen that the regeneration is more effective at lower feed flow rates at a given heating temperature.

\subsection{Effect of pre-heating the feed solution before inlet}

As shown in the previous section the thermal performance ratio and change in concentration is much lower at higher concentration desiccant solution operations. In order to improve the performance per-heating the salt solution before entering the regenerator was carried out using a solution heat exchanger. The pre heating raised the temperature of the inlet feed solution to $\sim 70^{\circ} \mathrm{C}$, which under normal conditions vary between $25{ }^{\circ} \mathrm{C}-30{ }^{\circ} \mathrm{C}$.

Figure 7 illustrates the effects of pre-heating the $\mathrm{LiCl}$ aq. solution at $34 \%$ inlet concentration and a heating temperature of $80^{\circ} \mathrm{C}$ on the performance of the regenerator. It can be observed that pre-heating the feed improves the thermal performance ratio; the increase in the performance ratio is enhanced at higher feed flow rates. It can also be 
observed that upon pre-heating the difference between the feed inlet and outlet concentration decreases. The decrease is more significant at lower feed flow rates.

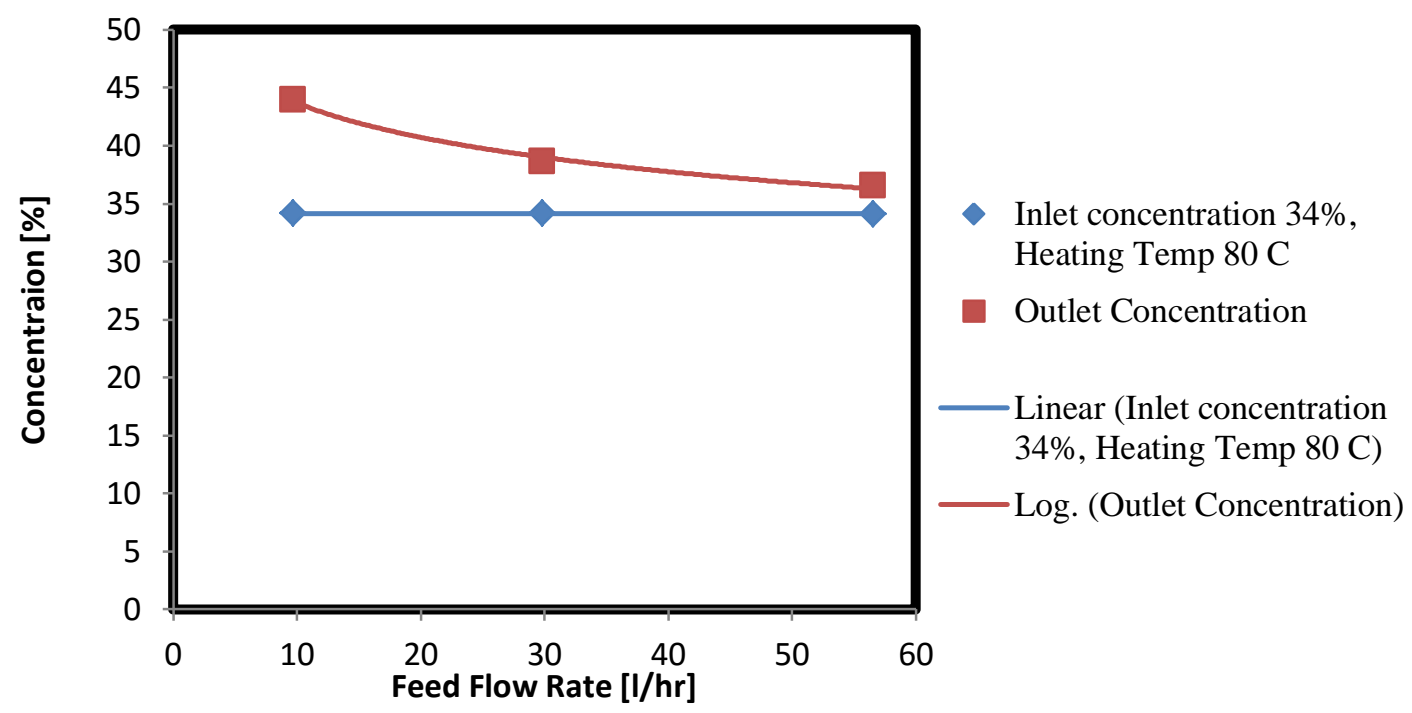

Fig. 6: Inlet and outlet concentration of desiccant [\%] against varying feed flow rate at $34 \%$ inlet concentration; heating at $\sim 80^{\circ} \mathrm{C}$.
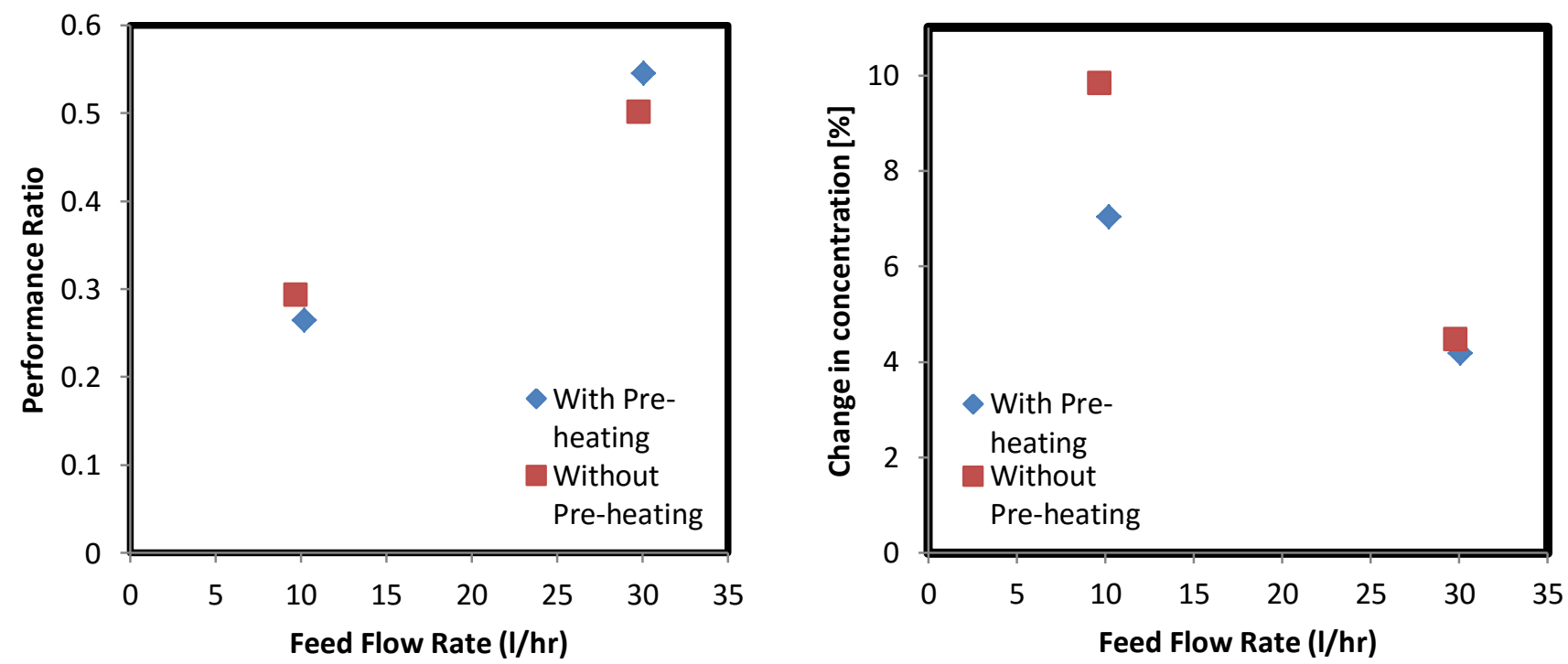

Fig. 7: Thermal performance ratio against varying feed flow rate with and without pre-heating for $34 \%$ inlet concentration (left), and change in concentration against varying feed flow rate with and without pre-heating for $34 \%$ inlet concentration (right).

\section{Comparison of Change in Concentration: V-MEMD Operations for High Concentration Versus Low Concentration at Inlet.}

It can be observed from Figure 8 that the feed flow rate has a greater effect on the change in concentration as compared to the effects of the change in heating temperature. The change in the concentration at a given heating temperature, and the feed flow rate decreases with an increase in feed flow rate. This can be attributed to the reduced time of stay of the desiccant inside the module spacer for vaporization. At higher concentrations of $34 \%$ the change in concentration becomes lower at the fixed feed flow rate and heating energy as compared to the lower concentrations of $8 \%$, $15 \%, 22 \%$. It can also be observed that the change in the concentration decreases with the increase in inlet solution 
concentration. The equilibrium vapor pressure decreases with the increase of salt solution concentration. The concentrated desiccant has a lower equilibrium vapor pressure compared to the diluted one [16].

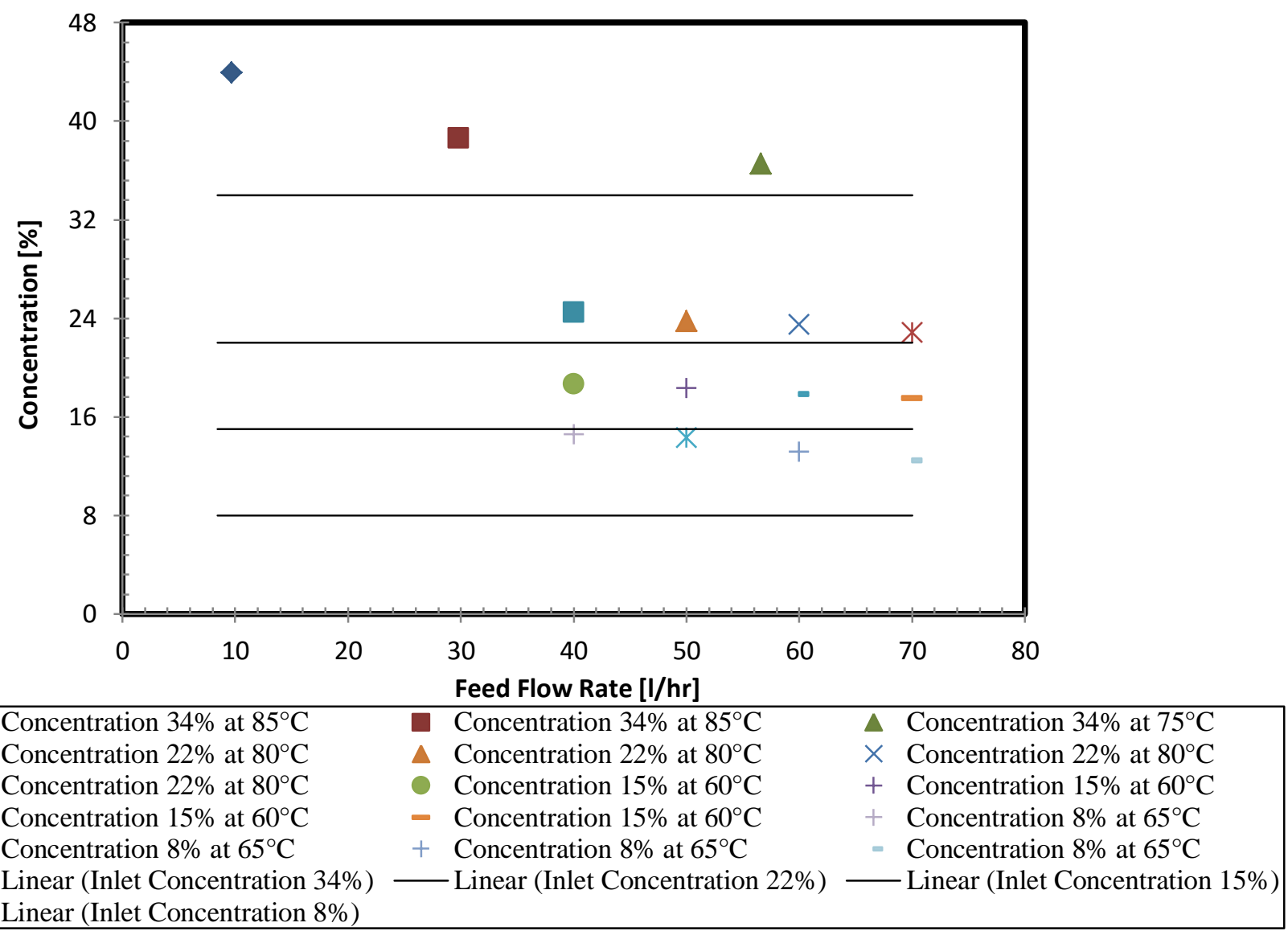

Fig. 8: Inlet and outlet concentrations versus various feed flow rate.

\section{Conclusion}

The thermal performance ratio and the change in concentration [\%] were measured experimentally with respect to varying feed flow rates employing lithium chloride as the desiccant at higher inlet concentration of $34 \%$; feed flow rate was varied between $10 \mathrm{l} / \mathrm{hr}$ and $601 / \mathrm{hr}$, and heating temperature ranging between $75^{\circ} \mathrm{C}$ and $85^{\circ} \mathrm{C}$. The results indicate that the thermal performance ratio of the 2-stage V-MEMD regenerator increases with the increase in feed flow rate and the heating temperature. However, with the increase of feed flow rate, the difference between the feed concentration at the inlet and the outlet of the regenerator drops significantly.

The results also shows that when the salt solution is pre-heated prior to its entry into the regenerator, the performance ratio increases for a constant feed flow rate, feed concentration and heating temperature. However, the change in concentration decreases when the feed solution is pre-heated. The improvement of the performance ratio upon preheating is higher at higher feed flow rates, and for higher heating temperature. The effect of pre heating on the change in concentration decreases at higher feed flow rates.

Finally, the thermal performance ratio and the change in concentration results for $34 \%$ inlet concentration were compared with the previous work by Kumja et al. and validated their prediction about the performance ratio and the change in concentration at higher feed concentration [14]. The comparison suggests that the thermal performance ratio is a function of initial feed concentration, heating temperature and the feed flow rate. The thermal performance ratio decreases drastically at higher feed concentrations and the change in concentration also decreases significantly at higher feed concentration. 
The study shows that the V-MEMD system performs well even at higher concentration (34\%) feed solution and is able to concentrate the feed solution to desired levels. However the overall performance is much lower compared to the operations involving lower inlet feed concentrations.

\section{Acknowledgements}

The authors would like to thank A* Star, MND, and Building Construction Authority (BCA), Singapore for funding this research work under the grant (Project No. SERC 112176 0024). I will also like to thank IGS, NTU for the Research Scholarship and ERI@N for continuous support throughout the research.

\section{References}

[1] A. Omer, "Energy, Environment and Sustainable Development," Renew.Sustain.Energy, Rev. 12, pp. 2265-2300, 2008.

[2] D. E. K. D. Kolokotsa, "A roadmap towards intelligent net zero and positive-energy buildings," Sol. Energy, vol. 85, pp. 3067-3084, 2011.

[3] D.P.Wyon, "The effects of indoor air quality on performance and productivity," Indoor Air, vol. 14, pp. 92-101, 2004.

[4] G. G. C. S. A.H. Abdel Salam, "Performance analysis of a membrane liquid desiccant air-conditioning system," Energy Build, vol. 62, pp. 559-569, 2013.

[5] X. L. Y. J. T. Zhang, "Performance optimization of heat pump driven liquid desiccant dehumidification systems," Energy Build, vol. 52, pp. 132-144, 2012.

[6] F. K. A. Bakhtiar, "A novel method to evaluate the performance of liquid desiccant dehumidifier system," Energy Build, vol. 44, pp. 39-44, 2012.

[7] E. C. W.Kessling, "Energy storage for desiccant cooling systems component development," Sol. Energy, vol. 64, 1998.

[8] C. S. A.H. Abdel Salam, "Capacity matching in heat pump membrane liquid desiccant air conditioning systems," Inl. J. refrig, vol. 48, pp. 166-177, 2014.

[9] N. L.Z. Zhang, "A heat pump driven and hollow fiber membrane-based liquid desiccant air dehumidification system: modelling and experimental validation," Energy, vol. 65, pp. 441-451, 2014.

[10] C. S. G. G. A.H.Abdel Salam, "Thermo-economic performance of a solar membrane liquid desiccant air conditioning system," Sol. Energy, vol. 102, pp. 56-73, 2014.

[11] G. C. R. B. K. Mahmud, "Performance testing of a counter cross flow run-around membrane energy exchanger RAMEE system for HVAC applications," Energy Build, vol. 42, pp. 1139-1147, 2010.

[12] S. B. G. L. Wolfgang Heinzl, "Industrial modules for MED Desalination with polymer surfaces," Desalination and water treatment, vol. 42, pp. 177-180, 2012.

[13] E.-D. H. E. T. Hisham, "Multiple-effect evaporation desalination systems," Thermal ananlysis, Desalination, vol. 125, pp. 259-276, 1999.

[14] M. H. Choo, "Experimental study on the performance of membrane base multi-effect dehumidifier regenerator powered by solar energy," Energy Procedia, vol. 48, pp. 535-542, 2013.

[15] M. R. Conde, "Properties of aqueous solutions of lithium and calcium chlorides: formulations for use in air conditioning equipment design," International Journal of Thermal Sciences, vol. 43, pp. 367-382, 2004.

[16] AIL. Research Inc., U.S. Patent 7269966. 